\section{NETWORKING ISLAM: THE DEMOCRATISING POTENTIAL OF NEW TECHNOLOGIES IN RELATION TO MUSLIM COMMUNITIES}

\section{Abstract}

This article critically examines existing theory on the uses of new technologies by minority communities to make connections, transforming identities and challenging traditional notions of community. As with the debate about new technologies in general, a utopian and dystopian position has prevailed. Has the development of new technologies, as the optimists predict, opened up access and liberated minority groups from established structural constraints? Has the Internet been a tool for mobilisation both socially and politically? Or as theorists such as Robins and Webster (1999) argue does the development and use of new technologies reinforce and maintain traditional hierarchies both within and without minority communities. What are the consequences of global and technological processes on already excluded groups? After examining these theories, the article applies them to Muslim communities in Britain by situating them within the worldwide community of Muslims (the Umma). Suggesting that there has been perhaps too much emphasis on theorising about the potential of new technologies with few empirical studies to support arguments that new technology provides for greater connectivity between dispersed groups, the article argues that an empirical approach will reveal how far minority communities are able to access new technologies for these purposes or whether these are limited to a privileged educated elite. Such questions are important for identifying the barriers to access and suggesting ways of enabling and empowering people in a new media environment.

ELIZABETH POOLE

Elizabeth Poole lectures in Media and Cultural Studies at the School of Humanities and Social Science, Staffordshire University, e-mail:

E.Poole@staffs.ac.uk. 


\section{Introduction}

The proliferation of NICT's (New Information and Communication Technologies) has, particularly in recent years, been accompanied by rhetoric regarding their both democratising and regenerating potential. The British Government, following America's lead, is committed to new technologies as a way of securing Britain's economic future and this has generated numerous reports and policies in all areas of Britain's social and public sphere to promote the adoption of IT. For example, a recent report from the Department of Trade and Industry (1999) entitled "Closing the Digital Divide: Information and Communication Technologies in Deprived Areas," the Minister for Small Business and E-Commerce, Patricia Hewitt talks of the "revolutionary" period we are living in, the "Information Age," how technology is transforming "all our lives" and the need for Britain to embrace technological change if it is to remain competitive and prosper in the global economy.

This type of discourse predominates in both the political and economic spheres. Within these and other public arenas, attention has also been paid to the empowering nature of technologies for different "minority" groups; this includes their potential to offer minority groups a mediated space in which they can produce their own material and where they have been previously marginalised in mainstream media forms; equally theories abound about a disembodied cyberspace where people can throw off structural constraints and create new configurations of community on the basis of chosen identities. In this paper I want to question whether NICT's are performing this role for minority groups by examining research which explores the social context of community use of media goods in everyday practices. In particular, I want to then raise questions about the appropriation and consumption of new media products amongst British Muslims. I want to emphasise that this is work in progress, raising issues for future research. However, the questions raised here are based on preliminary interviews with sections of the Muslim community in Stoke-on-Trent, Staffordshire. On this basis, I want to argue that theories that suggest the Internet has become prolific amongst diasporic groups as a way of maintaining contact and reproducing community are as Gillespie (2000) has suggested "exaggerated and romanticised" for the majority of disadvantaged communities in the UK (and of course globally) due to socio-economic, and cultural constraints. However, there is evidence of technocultural practices that are contributing to the formation and maintenance of networks along social and political lines.

\section{Existing Theory and Research}

The limited research that exists into the use of technologies amongst minority groups fall into two categories, the more theoretical work which explores the networks of transnational communities and the role of media forms supporting particular diasporic formations; and administrative research which examines the demographic patterns of uptake of NICT's by minority communities within national contexts. There is more evidence of the latter in America where various studies by both public and private groups show how African Americans and Hispanics are marginalised in both computer access and usage (Abrams 1997; Novak and Hoffman 1998, NTIA Digital Divide Study 2001) but a difference (with white groups) which according to Smikle (2000) appears to be closing, at least in terms of economic ac- 
tivity on the Internet. Studies in Britain on multimedia and society rarely allude to minority usage, for example the Department of Trade and Industry's IT for All survey of 1998, only picked up 142 respondents from a minority ethnic group background out of 3103 respondents in total, equally studies on the social exclusion of minorities have not, in the past, seen access to IT as an important aspect of this exclusion. I will come back to some of the findings that do exist later to illustrate the lack of resources available to minority groups and concentrate here on transnational communities.

The development of ICT's has both been an accelerator and a consequence of globalisation, allowing for a massive increase of cultural flows across time and space. The development of electronic forms of communication have resulted in theories of the "global village," a utopian conceptualisation of a world where information flows freely and there are no barriers to accessing this (Gates 1995; McLuhan 1964; Negroponte 1995). Several studies have emerged which attempt to map these connections in the form of transnational cultures, as with Vertovec's (2000) transnational community programme, which aims to explore "globalisation from below." Others have explored the role of electronic forms of media such as television and videos in creating "embryonic public spheres" amongst, for example, mainly Hindu South Asians (Gillespie 1995) and Iranians (Sreberny 2000), both communities living in London. The role of the Internet as a resource for diasporic communities has been studied in relation to the Indian diaspora in America (Mallapragada 2000), communities of users in India (Sundaram 2001), the Iranian diaspora (Khosravi 2000), the Turkish diaspora (Robins and Aksoy 2000) and in particular, transnational flows in the Arab world (Alterman 1998; Anderson 1997; Burkhart 1998; Dresch et al 2000; and Rathmell 1997), each of these "communities" having distinctive features in their organisation and political, cultural and economic positions. These studies have suggested that these forms of media serve specific social and cultural needs of diasporic groups who are continually living in a state of "unsettled negotiation" as a result of "cultural translation" (Bhabha 2000,2).

These studies argue that the Internet, due to its immediacy, interactivity, and unlimited reach allows diasporic groups to experience community in a new way, transcending national boundaries, re-representing and reworking their collective memories, reconstituting communities along chosen (and often multiple) affiliations (rather than territorial). Hence, this offers a safe environment for negotiating syncretic identities where groups are able to intervene in their own representation and articulate and recenter their own identity and history (Mallapragada 2000). The result is what Sundaram (2001) defines as "new landscapes" = the "reterritorialisation" of communities along transnational lines. The high take up of the Internet amongst diasporic communities is indicative, according to Mallapragada (2000), of the need for forms of reassurance and belonging in an uncertain environment.

According to both Mallapragada (2000) and Bunt (2000) an examination of these sites and their links can provide an indication of the specific identities different groups privilege, hence by mapping sites and communities of users, these trajectories can be identified. Sundaram (2001) identifies three typologies of the websites with different modes of address according to how they position themselves, (although there is a great deal of cross-over between them): (1) nationalist state, (2) 
transnational elite, and (3) space between market and state- social movement networks (cyberpublic). The struggle between these sites around definitions of identity is demonstrated by Bunt's (2000) work on Islam. Whilst religion has been one point of differentiation within diasporic cultural transformations, Islam is rarely studied as the central axes around which a community may reconfigure. Bunt's (2000) comprehensive research on "Islamic" websites, which he delineates according to symbols, language, and textual and ideological sources amongst other things, whilst also emphasising their diversity with respect to cultural, political and other specificities, provides an indication of the utilisation of the Internet by Muslims across the world. Bunt argues that the openness of the Internet, as well as allowing disenfranchised groups in the West to circumvent the mainstream media, also allows those marginalised within mainstream "orthodox" Islam to challenge this "authenticity" and clarify religious knowledge, circumventing authoritarian governments in the "Muslim world" and subverting hegemonic discourse along the lines of gender, sexuality, age, etc. Two examples are Queer Jihad, a website for homosexual Muslims and www.angelfire.com which is run by a group of Muslim women in Yorkshire to provide information and support in the face of negative press discourses on arranged marriages (Hellawell 2001).

The anonymity, then, provides a space for dialogue to take place, whether social, religious or political, in ways that may not have occurred before. The result, according to Mandaville $(1999,23)$, is an emergent postmodern Islam, a multifaceted experience which gives rise to both the reorganisation of religious knowledge and the "critical re-imagination of the boundaries of Muslim politics."

Hence, the web is also hailed as a way of mobilising people politically against different forms of hegemony, however work focuses mainly on the websites as texts with little attention to the users. Nielsen et al's $(2000,2)$ developing work on the Sufi Order in Islam, examining a number of media and cultural practices to identify how "Islam functions across boundaries of states, communities and ethnic groups," promises, then, to be very interesting in relation to this study.

\section{Why Muslims?}

Political Context. In the New World Order, since the collapse of communism, Islam has been constructed as the new enemy of the West in a bi-polar relationship around a conceptualisation which draws on Huntington's (1996) thesis of the "clash of civilisations" (see Hippler and Lueg 1995). The negativisation and exclusion of Muslims world-wide, resulting in "cognitive dissonance" over what means to be a "Muslim," has seen many turn to Islam for reassurance and in resistance to dominant narratives (Höijer 1998, 178). A mediated consciousness of the global demonisation of Muslims has resulted in religious identifications on the basis of worldwide inequalities (Poole 2001). Exclusions in the UK are partly based on a race relations paradigm in the allocation of resources based on its colonial past. Muslim identification is also then a mode of resistance against racial definitions of self.

Deprivation. Although actual statistics on Muslims social status are not currently available, in Britain, the majority of Muslims are from South Asian extraction, in particular Pakistanis and Bangladeshis. The latest statistics available show that that these two groups experience disproportionate disadvantage compared to both the white population and in comparison to other minority ethnic groups, 
both in terms of educational achievement, employment, health, and housing. For example, $80 \%$ of people with Pakistani or Bangladeshi origins live in households that have incomes lower than the national average compared to $28 \%$ of white people, $40 \%$ of African-Caribbean and Indian people, and $34 \%$ of Chinese people (SEU, 1998). Employment rates are lowest amongst those from Bangladeshi and Pakistani backgrounds at $36 \%$ and $42 \%$ respectively compared to $75 \%$ of white people (SUE 1998).

Religious Factors. One could argue that Muslims, through the concept of Umma -- already constitute a global community, transcending spatial, national and racial boundaries. This is supported by the concept of $d a^{\prime} w a$ - the missionary aspect of the religion, to spread the word spread of God.

For Muslims, then, as particularly deprived groups of peoples, subject to new cultural racism (Hall, 1992), it would appear that the Internet offers them not only a space for self-determination, but for building networks to overcome their marginal place in society and disaffection. The web is also a way for realising this imagined community, the Umma, hence Muslims in the West are targeted by the Muslim world which adds to globalisation process. Global regimes of power, it could be argued, are resulting in specific formations of diaspora amongst Muslims. This raises a further question, do Muslims, as religious groupings, constitute a diaspora? To answer this it is necessary to define the concept itself.

What Is Diaspora? Traditionally, diaspora has referred to a dispersed, dislocated people, for whom, having been uprooted, place becomes important. In this conceptualisation there exists the myth of the homeland, common origins, and a desire to return. For Brah (1996), this definition implies fixed origins, pure identities, which, previous to this contact were mutually exclusive. She incorporates a notion of journeying, however, unlike Gilroy's (1993) "double consciousness," it is the process of reliving these journeys through which cultures are continually contested and translated.

Throughout modernity, origins have been constructed around nationality, excluding immigrant groups, forcing diasporic groups to go about recreating "home" in the search for belonging. Hence we can apply Anderson's (1991) notion of the "imagined community" where a particular idea of community is constructed around certain histories and symbols, and practices. This notion is applicable to virtual communities in that they may exist solely on a macro level, hence they are imagined in that the participants never meet but the narratives may also help maintain the collective identities of communities sharing a locality, a mosque web site for example.

\section{The Concept of a Muslim Diaspora}

Cohen's (1997) definition of diaspora places limits around what constitutes a diasporic community with its emphasis on the desire to return to a homeland. He argues that Muslims' religion provides additional "cement" to bind their communities but religious groups do not constitute diasporas in themselves as there is no commonality in the desire to return to a single place.

Yet the increasing complexity of the migrationary experience makes it more difficult to talk of a single homeland for any group of people. Within diasporas, the journeys of people can be highly variant, and these experiences will be further 
differentiated by the political and social context of the country of settlement, and by class, gender, generation etc. Hence, the notion of a group with common origins and a single homeland becomes more problematic. The diversity of Muslims, a diversity that is reproduced on and off the Web, exists equally in so called national or ethnic diasporas. Yet we could argue that Muslims share a commonality of goals and practices based on spiritual belonging. If, as we are trying to argue, technology is increasingly allowing for the formation of diasporas along multiple points of identification: language, origins, religion, we can talk of Muslim diasporas if we define the concept, as with Gilroy $(1997,304)$, as a tool to "illuminate the transnational workings of identity formation" and for these groups it is the "Muslimness" which is often at the forefront of their identity and organisation. The structuring of social and institutional forms within these communities is being evidence of this.

If, as Brah (1996) suggests, a homing desire exists rather than a desire for homeland, Muslims can create a diaspora through journeys through cyberspace to an imaginary "homeland," a place of remembering and reconstituting faith and cultural practices -arguments which explain the supposedly usefulness and popularity of the Internet to Muslims. As Smart et al, argue (cited in Cohen 1997) Muslims are particularly interesting as they already reject the territorilisation of identity in their consciousness as a global faith, creating a collective memory on being the chosen people of God, this is their common origin. However, I do not want to replace one essentialist notion with another. We can talk of Muslim diasporas whilst recognising "the entanglement of genealogies of dispersion" with those of "staying put" (Sreberny 2000) which will be demonstrated by the focus group research.

Key questions for my research:

Is the Internet challenging current social and political structures?

Is it providing a democratised space?

On what basis has a community developed? Or are a number of dispersed individuals using the information provided on websites?

Are people delocalised in a global space? What local meanings and uses are made of the information?

Is technology changing the way minorities' life is experienced?

So far, the research and evidence quoted has suggested that the Internet has become a resource for political empowerment for minority groups and that these communities are increasingly formed within global spaces. Evidence clearly exists to support these claims, one example is the BLINK - the Black Information network, which aims to provide information for Asian, African and Caribbean people living in the UK. They also engage in campaigns, for example against world debt, and have formed a Share in the Anti Racism project which raises money to support black people experiencing racial harassment. The group claims to receive one and a half million hits a month (www.blink.org.uk) but who is using the site and what for? This, as Bunt (2000) acknowledges is difficult to quantify; his reliance on the number of hits as demonstrating popularity is problematic as it tells us nothing of how the sites are used, by whom or even whether each hit constitutes a different person. Equally much of the rhetoric does not take account of content. Many sites are still one directional, presenting information, and where dialogue appears, it often appears to be rather banal, a study of their uses and importance to the user communities is necessary to clarify this. 
A substantive literature already exists which questions not only the information society thesis but utopian visions of technological advancement which suggest that information flow, regardless of content, will empower us all equally and allow us to be producers of our own media (Lyon 1994; Preston and Kerr 2001; Schiller 1996; Webster 1996) There are a number of arguments to suggest that this use is minimal, at the moment unusual, and technology is simply reinforcing social structures, power relations and capitalist ideologies.

\section{Existing Power Structures in the Social World Are Reproduced in Cyberspace}

This is occurring on a global and national context. Within national contexts, official sites attempt to define the identity of their "nation's" people by circulating specific histories to the exclusion of large numbers of people who live or were born there. For example, Mallapragada's (2000) and Sundaram's (2001) work shows how Indian sites suggest universality but are constructed to create ideas about an authentic community, a specific formulation of a Hindu India which attempts to maintain a dominant hegemonic position in formulations of "India" amongst the diaspora.

The anonymity of the web raises a question of control, its apparently decentralised "nature" working to conceal centralised authority (Sundaram 2001). Many Muslim web sites are dominated by a male educated, middle-class elite and emanate from elite nations such as the USA (Bunt, 2000) Some interpretations are therefore marginalised as, in particular, governments propagate their own versions of Islam as a form of control. The Malaysian government has attempted to do this, and the investment of the Arab world in heritage building has also been documented (Dresch et al 2000). Governments are also able to block access to "offensive" material using filtering systems. This creates new kinds of cultural borders.

Globally Western capitalism is colonising the net and adopting practices and policies, which ensure its dominance. This is obviously supported by the structural constraints that prevent whole populations from taking advantage of any advances in technology let alone competing on any level.

For example, Anees $(2000,1)$, the editor-in-chief of Islamic portal "Huruf" (which represents an attempt to develop an Islamic network which recognises differentiation within common goals) claims Muslims, comparatively, maintain a peripheral presence on the net due to specifically disproportionate economic and technical capabilities. The Internet environment driven by market forces, then, reinforces the experience of being excluded.

The "digital divide" and the "information poor" have become clichés that are bandied around so often that they have lost any significant meaning, yet the statistics illustrate the reality of these conditions. The imbalances of power has been clearly demonstrated in a number of studies both within the UK and elsewhere. The recent UK Government funded Policy Action Team Report 15 (2000) found that the take up of ICT's in deprived neighbourhoods is lower than the national average, this particularly affects minority communities given that, as the Social Exclusion Unit (1998) and Performance and Innovation Unit (2001) reports have found they are more likely to live in deprived areas, be unemployed, have low incomes, poor housing, ill health and be victims of crime (with Muslims, particu- 
larly from Pakistan and Bangladesh showing the highest levels of unemployment, Brown 2000). Obviously, there are a number of complex and influential factors intersecting here, as amongst the population in general, which have an impact on the individual take up of new technologies but, as the Social Exclusion Unit (SUE) report argues, the economic situation of minorities is further exacerbated by institutional racism, language barriers and cultural factors, for example, access for women. With a disproportionately young age structure (only 3\% of Pakistani and Bangladeshi people are over 65 compared to $16 \%$ of white people), this is of concern given that other surveys have found young people most engaged with NICTs (SUE 1998). There is some evidence from studies in South London to suggest that minority ethnic access to youth training is also more difficult (SUE 1998).

Recent limited research (within the scope of the project) with Muslim women in Leicester (Hellawell 2001) provides evidence of a desire to embrace technology for support, expert information about central aspects of their daily lives including child care, health, and religion, and to communicate with family abroad, however, there are significant barriers to this, especially for women who are confined to the home. Government initiatives targeting excluded groups (UK On-line centres, WireUp communities) are still not reaching these especially marginalised people.

\section{Research Findings}

In Stoke-on-Trent, unemployment is high due to the decline of its manufacturing industrial base. A recent report showed Stoke to be the fourth least affluent local authority area in the country with only $0.3 \%$ of its population earning over $£ 60,000$ annually (Patrick Collinson, the Guardian, 11 August, 2001. Source: Barclays Private Clients).

Interviews with groups of young male Muslims (predominantly Pakistani) aged between 15-25 followed recent disturbances across the North of England as a response to increasing activity by white extremists. I will focus on two examples from these interviews to illustrate both the complexity of identity formations and the use of technology within these social configurations.

Firstly, a question about how they would define their own identity produced an initial response of "Pakistani Muslims" following a discussion on who the National Front were targeting and their own relations with other minority groups in the area, including Kosovan and Iraqi Muslims to whom there was some resentment based on the allocation of resources in the local area. After some discussion about being born in Britain the official response of the group was "British Asians or British Muslims" although some resisted this "official formulation" and insisted on "British Muslims." However this was followed by a discussion on allegiances to Pakistan.

Yet in the context of recent tensions, the group emphasised their "Muslimness" and their protection of each other as "brothers;" "if anyone made one phone call now ... everyone would be here in minutes ... all you've got to say is the NF are here ... because that's what we call in our language, intifada. As Muslims we are together ... not as Pakistani's, we don't give a shit about each other as Pakistani, we don't say Pakistani brother but when we say Muslim, we say Muslim brother."

This is further complicated when one of the participants tried to empathise with white people: "When I was in Pakistan with my Dad I saw a sign 'British 
homes' and I said to Dad 'what's going on here?' and he said 'only white people live there and there's a church and everything' and I got so angry, why is there a church in our country but it's the same thing over here...."

These young men clearly identify with a number of subject positions, proclaiming their Britishness but negotiating between multiple attachments, a state which Bhaba $(2000,3)$ calls, "in the middle of difference." Evidence from these interviews and previous work I have done with young Muslims in Leicester (Poole 2001) demonstrates the syncretic complexity of identity which can be described as "transcultural mixture"(Gilroy 1997). What would appear to be contradictory statements made by these young people about their identities demonstrates their fragmentary and plural states but also the ease at which they make transnational, national and local identifications. Deterritorialisation appears to be a more accurate concept than displacement then - "the collapse of a fixed link between identity, culture, existence and a single place" (Khosravi 2000). This illustrates the usefulness of a concept of diaspora in describing these groups which recognises the intersections of identity which are continually reconstituted in different circumstances; a process Gilroy $(2000,440)$ describes as "cultural mutation and restless (dis)continuity" but recognises the limits of the language used as tools to describe a such a complicated transformatory process.

However, what is significant here is the proclamation of and investment in religious identity, putting this forward as an assertive group identity and displacing other categories. It is this aspect of identity particularly under attack (from the National Front and British National Party) and this aspect which gives these Muslims strength and the principle on which they are organised. It is their exclusion from being part of "the nation" that strengthens these allegiances, as one group member commented that although they see themselves as British, the majority community does not. In this case, identity, even if momentarily, becomes concretised for political effect as a "context-specific construction" (Brah 1996, 124).

Brah's (1996) "diaspora space" then, which encompasses not just the diasporic subject but the relational dynamics of others which play a role in constructing it and therefore take account of relations of power, is a concept that offers an important framework for understanding how the local/global figure in political behaviour.

I want now to examine how technologies are being used in the daily practices of the community, allowing it to be both imagined and experienced in a more collective and enhanced way. However, at this time, the Internet is not a significant resource for this. These young people are, in the main, only able to access the Internet infrequently at school. This supports evidence from America that shows differences between African-American and white American access and usage of computers is a result of more white children (or students) having access at home $73 \%$ vs. $32.9 \%$ (due to income differentials), but also that they are more able to access computers within wider social networks and localities than their AfricanAmerican counterparts (Novak and Hoffman 1998).

The lack of access that these young people have to computers explains their uses of mobile phones as opposed to e-mail as their main means of communicating with each other. One of the participant's mother described the phones as "colostomy bags" as they are always attached to their trousers. These phones are a neces- 
sary part of the social cultural practices of young males to feel part of their community. It is the mobility, interactivity, efficiency and economy, the "pay as you go factor" which is particularly appealing to them. This means that even if only a couple of members of each grouping has them, their social formations allow the group to keep in touch with the movements of other groups in the area. This fits with research that shows that the mobile phone have become a "technology of necessity" and certain socio-economic factors such as income and education are no longer significant in their take-up. However, age is a vital predicator of adoption, as well as the attributes of the phones and their perceivable benefits to individuals and groups, properties including compatibility with existing values, and simplicity of use (Leung and Wei 1999).

Some of these benefits offered by the phones relate to their contribution to "reciprocal interdependence" (Leung and Wei 1999, 224). The phones serve an important political function recently demonstrated when they were used to organise a march in response to rumours that the NF would be gathering in Stoke.

Interviewer: How did you all contact each other?

Phones.

By our mobiles.

I was at work and I received a text message saying 'The NF are arriving tomorrow please be ready.

A text went round saying that tomorrow, well, Saturday, it said the date and, em, at this time come up and send it to 7 brothers.

Interviewer: Who sent it?

It was organised from this little Chico, it was organised.

Interviewer: Is he a leader?

We don't have leaders amongst us really so what it is when everyone got together, just because we don't want to get told... You know our parents were standing round and you know we've got houses here and everything like that so we said let's make it peaceful and we'll do a march ourselves.

These telephone networks exist to cousins, family, and friends within and outside the local area, and although the group said brothers could have been contacted in Birmingham, Bradford and Oldham there was a desire to not let things get out of hand, to contain the issue locally. These practices could therefore be described as "spatially conscious counterstrategies" (Soja 1985).

What is also significant, is the principle on which the groups are organising themselves politically. The texts were sent to Muslim brothers, and there was evidence of the subsuming of other internal differences to order to promote this idea of the "imagined community" and set boundaries around it.

This provides an indication of the role NICT's can play in the struggle to both define oneself, and to protect oneself, strengthening the community on this basis. These young people experience both "the fit and non-fit" (Sreberny 2000, 181) of their multilocationality and are politically asserting their identity as British and Muslim in the face of exclusion as a point of self worth as a way of saying the myth of return is no longer viable.

These Muslims are using mobile phones to create their own local, national and transnational communities in which geographical, cultural, political spaces of opposition are being reworked and renewed through new forms of technology which are relatively unconstrained by any state control.

This also provides an indication of the factors involved in the take-up and adoption of new media products, that the outcomes of technological development are unpredictable and the consumption of these products will vary widely on a global 
scale. The Internet is currently inaccessible and impractical whilst the phones allow members of the community to organise themselves more easily, more quickly and have more control over shaping their own political structures. What it does illustrate is the growing importance of electronic networks in our social, political relations in contemporary society and how existing practices, supported by electronic forms, such as business networks, may be transformed by new media technologies.

The use of these networks in providing community support offers an outlet for minorities to participate in the new economy.

If we come back, then, to theories of cultural imperialism, it is clear these technologies are developed for capitalist reasons yet commodities can be used for resistance -an example of the push and pull of globalisation that people both buy into and reject commodities - resulting in a translocal experience (Robins and Slack cited in Gilroy 1997). New media forms are invoking social solidarity in new ways, and new media cultures are clearly evident but we need to be cautious in being over ambitious with regards to celebrating their emancipatory potential without attending to the lived realities of diasporic groups. Equally, we should not reify ethnicity as a reason for technological take-up, other factors are clearly influential, such as age, but ethnographic work can reveal the uses and relevance of such technology for groups along different dimensions of identity.

\section{Conclusion}

To summarise then, there is some contestation over whether Muslims constitute a diaspora, however, I am arguing that the concept of diaspora is useful, in this case, in that it recognises the multiplicity of identity. To talk of the Muslim diaspora is not to fix this as a singular identity but show how this aspect of identity has been mobilised politically by both the producers and subjects of discourse whilst taking account of the inflections of disparate identities within it. The "we," the "us," "the community" is constructed and mobilised through political and cultural practice as a result of material conditions, the production of historical and global narratives and local contexts.

Technological media forms are being used by diasporas to help construct and maintain both social, cultural, religious and political networks which are then transforming community dynamics. However, the evidence so far shows that we cannot assume that the take up amongst different groups will be symmetrical just because a democratic potential exists. This needs mapping amongst different diasporic groups and this is why the work we are doing is so important in ensuring that this potential is realised.

\section{References:}

Abrams, Alan. 1997. Diversity and the Internet. Journal of Commerce, June 26.

Alterman, Jon. 1998. New Media, New Politics: From Satellite TV to the Internet in the Arab World. The Washington Institute for Near East Policy, Policy Paper No. 48.

Anderson, Benedict. 1991. Imagined Communities: Reflections on the Origins and Spread of Nationalism. London: Verso.

Anderson, Jon.W. 1997. Globalising Politics and Religion in the Muslim World. Available at http:// www.al-bab.com/media/internet.

Anees, Munawar A. 2000. Huruf: An Interactive Global Portal. Available at http:// isim.leidenuniv.vl/newsletter/6/media/3.html. 
Bhabha, Homi K. 2000. Minority Culture and Creative Anxiety. Keynote Speech at Reinventing Britain. London: The British Council. Available at http://www.britishcouncil.org.

Brah, Avtar. 1996. Cartographies of Diaspora: Contesting Identities. London: Routledge.

Brown, Mark. 2000. Religion and Economic Activity in the South Asian Population. Ethnic and Racial Studies 23, 6, 1035-1061.

Bunt, Gary. 2000. Virtually Islamic: Computer-mediated Communication and Cyber Islamic Environments. Cardiff: University of Wales Press.

Burkhart, Grey. 1998. National Security and the Internet in the Persian Gulf Region. Available at http://www.georgetown.edu/research/arabtech/pg198-1.html.

Clifford, James. 1997. Routes: Travel and Translation in the Late Twentieth Century. Cambridge, MA: Harvard University Press.

Cohen, Robin. 1997. Global Diasporas. London: Routledge.

Dresch, Paul, James Piscatori, and Madawi al-Rasheed. 2000. Connection and Imagery: Transnational Culture Flows and the Arab Gulf. Transnational Communities Programme: ESRC. Available at http://www.transcomm.ox.ac.uk.

Gates, Bill. 1995. The Road Ahead. London: Viking.

Gillespie, Marie. 1995. Television, Ethnicity and Cultural Change. London: Routledge.

Gillespie, Marie. 2000. Transnational Communications and Diaspora Communities. In S. Cottle (ed.), Ethnic Minorities and the Media, 164-178. Buckingham: Open University Press.

Gilroy, Paul. 1993. The Black Atlantic: Modernity and Double Consciousness. London: Verso.

Gilroy, Paul. 1997. Diaspora and the Detours of Identity. In K. Woodward (ed.), Identity and Difference, 301-346. London: Sage.

Gilroy, Paul. 2000. The Black Atlantic as a Counterculture of Modernity. In K. Owusu (ed.), Black British Culture and Society, 439-452. London: Routledge.

Hall, Stuart. 1992. The Question of Cultural Identity. In S. Hall, D. Held, and T. McGrew (eds.), Modernity and its Futures, 274-325. London: Polity Press.

Hellawell, Samantha. 2001. Beyond Access. ICT and Social Inclusion. London: Fabian Society.

Hippler, Jochen and Andrea Lueg. 1995. Conclusion: Dealing with Islam. In J. Hippler and A. Lueg (eds.), The Next Threat: Western Perceptions of Islam, 154-158. London: Pluto Press.

Huntington, Samuel. 1996. The Clash of Civilisations and the Remaking of the World Order. New York: Simon and Schuster.

Khosravi, Shahram. 2000. www.Iranian.com. An Ethnographic Approach to an Online Diaspora. Available at http://isim.leidenuniv.nl/newsletter/6/media/2.html.

Leung, Louis and Ran Wei. 1999. Who are the Mobile Phone Have-nots? Influences and Consequences. New Media \& Society 1, 2, 209-226.

Lyon, David. 1994. The Information Society: Issues and IIlusions. London: Polity.

Mallapragada, Madhavi. 2000. The Indian Diaspora in the USA and Around the Web. In D. Gauntlett (ed.), Web Studies: Rewiring Media Studies for the Digital Age, 179-185. London: Arnold.

Mandaville, Peter. 1999. Digital Islam: Changing the Boundaries of Religious Knowledge? International Institute for the Study of Islam in the Modern World, March.

McLuhan, Marshal. 1964. Understanding Media. London: Routledge and Kegan-Paul.

Morley, David and Kevin Robins. 1995. Spaces of Identity: Global Media, Electronic Landscapes and Cultural Boundaries. London: Routledge.

Negroponte, Nicholas. 1995. Being Digital. London: Coronet Books.

Nielsen, Jorgen, Galina Yemelianova, and Martin Stringer. 2000. Ethnicity, Politics and Transnational Islam: A Study of an International Sufi Order. Transnational Communities Programme: ESRC. Available at http://www.transcomm.ox.ac.uk.

Novak, Thomas P. and Donna L. Hoffman. 1998. Bridging the Digital Divide: The Impact of Race on Computer Access and Internet Use. Available at http://www2000.ogsm.Vanderbilt.edu/ papers/race/science.htm.

NTIA Digital Divide Study. 2001. Falling through the Net: Defining the Digital Divide. Available at http://www.ntia.doc.gov. 
Performance and Innovation Unit. 2001. Improving Labour Market Achievements for Ethnic Minorities in British Society. London: Cabinet Office.

Policy Action Team15. 2001. Closing the Digital Divide: Information and Communication Technologies in Deprived Areas. London: DTI.

Poole, Elizabeth. 2001. Interpreting Islam: British Muslims and the British Press. In K. Ross (ed.), Black Minority Ethnic Audiences, 67-86. London: Ashgate.

Poole, Elizabeth. Forthcoming 2002. Reporting Islam: Media Representations of British Muslims. London: I.B.Tauris.

Rathmell, Andrew. 1997. Netwar in the Gulf. Available at http://www.infowar.com/class-3/clas3q.html-ssi.

Robins, Kevin and Asu Aksoy. 2000. Negotiating Spaces: Media and Cultural Practices in the Turkish Diaspora in Britain, France and Germany. Transnational Communities Programme: ESRC. Available at http://www.transcomm.ox.ac.uk.

Schiller, Herbert. 1996. Information Inequalities: The Deepening Social Crisis in America. London: Routledge.

Social Exclusion Unit. 1998. Minority Ethnic Issues in Social Exclusion and Neighbourhood Renewal. London: Cabinet Office.

Soja, Edward. 1985. Regions in Context: Spatiality, Periodicity and the Historical Geography of the Regional Question. Environment and Planning D: Society and Space 3, 2, 175-90.

Smikle, Ken. 1999. The Buying Power of Black America. Target Market News Inc. Chicago. Available at http://www.targetmarketnews.com.

Sreberny, Annabelle. 2000. Media and Diasporic Consciousness: An Exploration among Iranians in London. In S. Cottle (ed.), Ethnic Minorities and the Media, 179-196. Buckingham: Open University Press.

Sundaram, Ravi. 2001. Beyond the Nationalist Panopticon, the Experience of Cyberpublics in India. Available at http://www.telfonica.cs/fat/esundara.html.

Vertovec, Steve. 2000. Transnational Communities Programme (ESRC). Available at http:// www.transcomm.ox.ac.uk

Webster, Frank. 1995. Theories of the Information Society. London: Routledge. 